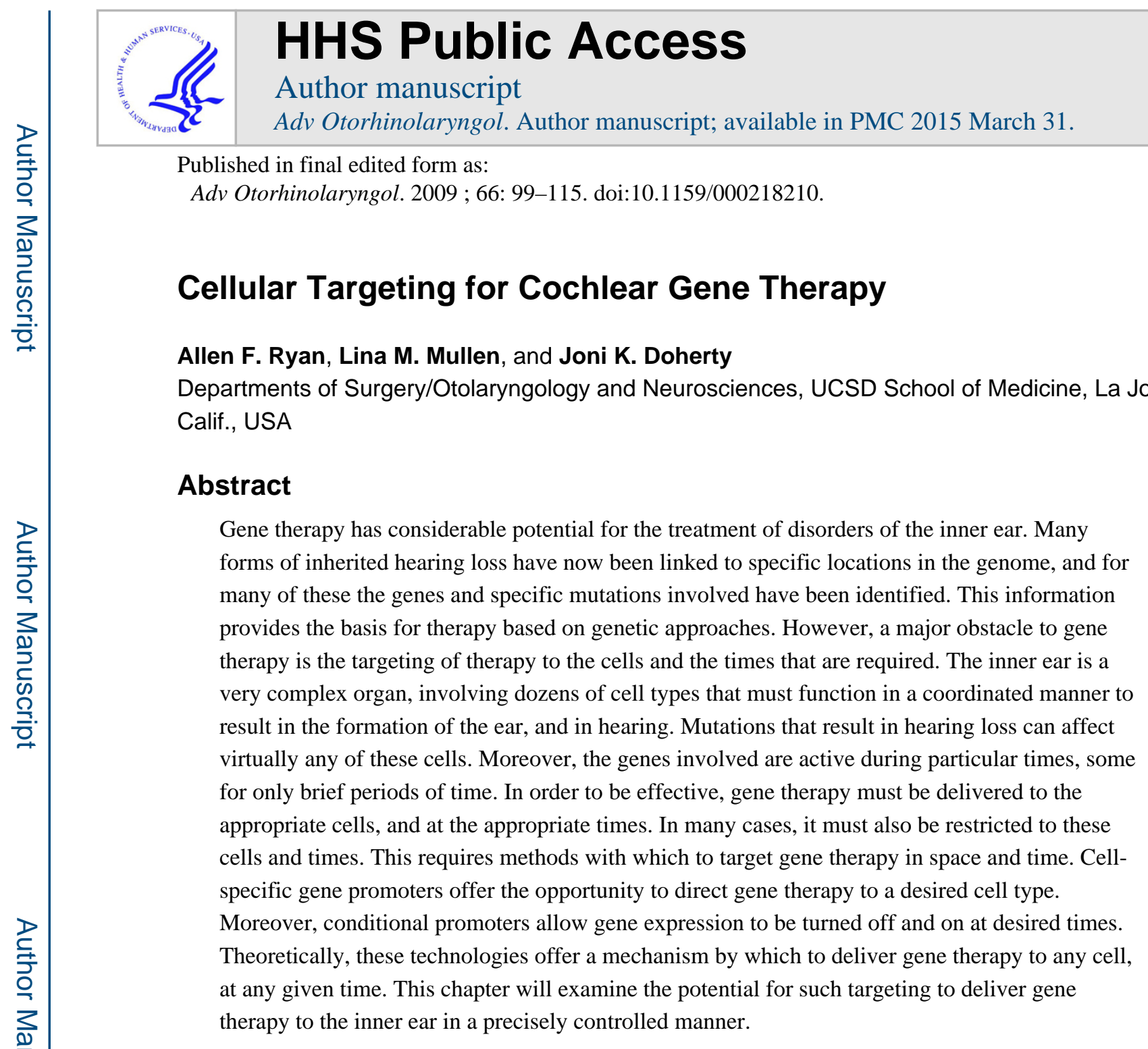

\title{
Introduction
}

While gene therapy has great promise for the treatment of disease, delivery has proven to be one of the greatest challenges to its application [1]. Part of this challenge is providing sufficient levels or durations of gene expression to influence a disease. However, a perhaps more crucial difficulty is targeting therapy to the cells that require treatment, and at the times that are necessary for it to be effective. This is especially important in complex tissues that contain many cell types, such as the inner ear, or during development when gene expression events and cells are changing rapidly. Gene therapy delivered to the wrong cell type, or at the wrong time, could be ineffective or even harmful [2].

Fortunately, tools with which to address these issues exist within the genome itself. All genes contain regulatory elements that control when and where a gene is expressed [3]. Many such regulatory elements, including gene promoters, enhancers and repressors, are

Copyright @ 2009 S. Karger AG, Basel

Allen F. Ryan, PhD, ENT, 0666, UCSD School of Medicine, 9500 Gilman Drive, La Jolla, CA 92093 (USA), Tel. +1 8585344594 , Fax +1858534 5319, afryan@ucsd.edu. 
cell-specific in that they limit gene expression to a subset of cells in the body. Many of these regulatory sequences also limit expression to a particular period of time. Almost all gene promoters are subject to regulation that controls the level of gene expression. Some regulatory elements also respond to factors that can be delivered to cells in an autocrine manner, permitting control by exogenous application of an appropriate factor. Finally, many viruses contain regulatory elements that control gene expression in their mammalian host cells. Harnessing these natural regulatory mechanisms makes it possible, at least in theory, to tailor gene therapy to any cell at virtually any time, and to regulate the level of transcript expression in a fairly precise manner.

\section{Mechanisms of Gene Regulation}

Gene expression, and the functions of mRNA and proteins that are the products of genes, can be regulated at many stages. An initial step in gene transcription is the exposure of genomic DNA, without which regulatory and transcriptional complexes cannot operate. This occurs primarily through the positioning of nucleosomes, around which the DNA is coiled, to allow access by regulatory and transcriptional proteins. Exposure of DNA is strongly influenced by the acetylation and methylation state of histones [4]. These nuclear proteins make up the nucleosomes and are critically involved in packaging DNA within the nucleus. Acetylation of primarily the $\mathrm{N}$-terminal glycine of histones by acetyltransferases reduces their affinity for DNA, thereby decreasing their density and increasing access for transcription factors (TFs) and RNA polymerase to their binding sites within the gene [5]. Histones can also be affected by amino acid methylation [6]. Histone methylation is most often associated with reduced transcription due to increased histone density and recruitment of silencing RNA and proteins. In its ultimate form this process results in the formation of dense heterochromatin leading to gene silencing. However, some methylation patterns of certain histone residues can reduce nucleosome density and increase transcription [7], thus the arrangement of nucleosomes within a cell's nucleus helps to determine the genes that can be expressed in that cell.

The identity of cells is in large part determined by the subset of the genome that is transcribed in the cell. Part of determining the repertoire of genes that is available to a cell occurs via selective gene silencing. This can involve via semi-permanent increases in nucleosome density, a process mediated in part by histone methylation and de-acetylation as described above, or the more permanent formation of heterochromatin [6]. However, another major mechanism of silencing involves the methylation of DNA, primarily within gene promoters [8]. Such DNA methylation typically occurs in the CpG islands (clusters of CG dinucleotides) that are associated with transcription start sites of many genes. However, even genes lacking $\mathrm{CpG}$ islands can be subject to silencing via methylation, especially in stem cells [9].

If their unmethylated DNA is exposed, the primary active regulation of genes occurs at the stage of transcription into mRNA. Transcription is mediated by RNA polymerase II and other members of the core transcriptional complex, which bind to the DNA at the transcriptional start site. The activity of the transcriptional complex is influenced by various TFs that bind directly to DNA at more diverse locations within the gene. TFs are 
characterized by protein domains that bind to specific DNA sequences. They also typically contain protein-binding domains. A transactivation domain can interact directly with the transcriptional complex and influence the activation of RNA polymerase II. Alternatively, a TF may bind to another protein that lacks a DNA-binding domain but possesses a transactivation domain. The differential regulation of gene transcription by TFs and associated proteins appears to be especially important during development [10,11].

Once a gene has been transcribed to mRNA, post-transcriptional regulation is also common. Translation from mRNA to protein can be regulated by a variety of processes. For example, microRNAs destabilize mRNA, leading to its degradation and silencing, and microRNAs also cooperate to regulate genes via combinatorial coding [12]. Differential mRNA splicing can result in a variety of proteins from the same initial RNA transcript. There are also, of course, many forms of post-translational modification of proteins including phosphorylation and cleavage.

Thus there are multiple layers of potential regulation that can contribute to the diversity in gene influence. Any of these could potentially be used as control mechanisms in gene therapy. However, the most attention has been focused on the interaction between regulatory DNA sequences and TFs [11]. The transcription of mRNA from a gene is largely controlled by cis-acting regulatory elements in the non-coding DNA sequences of the gene. Most such elements are DNA motifs, DNA sequences specifically recognized by the DNA-binding domains of TFs, and to which these proteins bind. Cis-regulatory elements in genes can be broadly divided into two categories: promoters and enhancers/repressors. Promoters serve as the binding site for the transcriptional complex including RNA polymerase II itself and the many associated TFs and TF-binding proteins that make up the core machinery for transcribing DNA into mRNA. Promoters are thus located at the transcriptional start site of a gene (fig. 1).

Enhancers and repressors function to regulate the rate of transcription. Through the binding of TFs and associated proteins, they can determine whether or not a gene is active in a particular cell type, as well as the level of transcription. These elements are often located 5' to the promoter, but they can be many thousands of bases distant. Regulatory sequences can also be present in transcribed but untranslated sequences of the gene such as the $5^{\prime}$-UTR or introns, particularly the first intron. They can also be located $3^{\prime}$ to the transcribed sequence. Once TFs and associated proteins are bound, these regulators are thought to influence transcription by interacting physically with the transcriptional complex and enhancing or repressing RNA polymerase activity. This interaction is mediated by a transactivation domain that is separate from the DNA-binding domain of the TF, or may be present in a TFbinding protein (fig. 2). A given gene typically has multiple enhancer and/or repressor elements (fig. 1).

TFs bind to the gene's promoter and to enhancers/repressors, typically in a combination of several factors at each. The combination of TFs that are present in a given cell play a major role in determining what DNA motifs are occupied, and how the gene will respond. Since the same DNA is present in all cells, the combination of TFs expressed by a cell is thus an important determinant of what genes will be expressed, and when they will be transcribed. 
While both promoters and enhancers/repressors can determine the cellular specificity of genes, enhancers of a gene are most often responsible for cellular specificity if a gene is expressed differently in different cells. A cell that expresses a certain combination of TFs may activate one enhancer, while another cell type expressing different TFs may activate a separate enhancer, which allows the gene to be regulated separately in each cell type. Other cell types that lack appropriate TFs will fail to activate the gene. Alternatively, different combinations of TFs and other regulatory proteins may act differently on the same enhancer. For example, many TFs have negative regulators that can either compete for the same or an overlapping binding site, or mask a transactivation domain and prevent interaction with the transcriptional complex. Such patterns of DNA-regulatory motifs, and the combinations of TFs and other regulatory proteins that bind to them, are sometimes referred to as the second genetic code [13].

The nuclear receptors comprise a special category of TFs. This includes a number of hormone receptors, such as the estrogen receptor, which when activated by their ligands will bind to promoters or enhancers/repressors to activate/silence a gene. Nuclear receptors permit the rapid regulation of gene activity. Binding sites for nuclear receptors can be engineered into the promoters of a gene therapy vector, allowing it to be regulated. A modified form of the estrogen receptor-binding sequence that is sensitive to tamoxifen is frequently used to produce vectors that are only transcribed in the presence of this molecule [14].

An artificial conditional system has also been engineered using bacterial and viral DNA sequences. For this method, sequence encoding a tetracycline-sensitive DNA-binding protein domain from Escherichia coli is fused to a sequence encoding a transactivating protein domain from Herpes simplex. In the resultant chimeric protein, binding of the DNAbinding domain is dependent upon tetracycline (or related compounds like doxycycline). Different forms of the protein either require (Tet-on) or are inhibited by (Tet-off) tetracycline for DNA binding. Once the DNA-binding domain is bound to its recognition sequence, which can be engineered into a gene-regulatory sequence, the transactivation domain activates the transcriptional complex on the promoter, thus activating the downstream gene. Regulation using the Tet-On and Tet-Off systems is somewhat tighter than with the estrogen receptor [15].

\section{Harnessing Gene Regulation for Gene Therapy}

The gene-regulatory processes outlined above can be utilized for gene therapy. For example, a promoter or enhancer that produces expression limited to a given cell type and/or developmental period can be used in a gene therapy vector. This would permit the vector to drive expression of a gene product only in that cell or at that time. Similarly conditional promoters, ones that express only in the presence of a particular nuclear ligand, can be used to turn on gene therapy for a brief period. In practice, there are difficulties with both approaches.

Regarding cell- or time-specific regulatory sequences, their isolation, identification and verification can be difficult. The core promoter of a gene and proximal enhancers are 
typically contained within the first few hundred base pairs $5^{\prime}$ to the locus at which mRNA transcription begins [16]. They are thus relatively easy to isolate and usually small enough to insert into a gene therapy vector. However enhancers, which most often determine cellular specificity, can be located much further upstream on the $5^{\prime}$ side of the gene, or within introns or other transcribed regions of the gene, or $3^{\prime}$ to the transcribed region $[17,18]$.

An initial step in the identification of regulatory elements is cross-species homology analysis. The regions of genes that are translated into protein are often quite homologous across species, because of the constraints imposed by protein function and the conservation of DNA codons. Regulatory regions of genes are also constrained, due to both structural constraints and conservation of DNA motifs that support the binding of TFs. However, the degree of conservation is much less than that seen in coding regions of DNA, since many TF recognition motifs display substantial sequence variation. This is especially true for enhancers and repressors. Even with these constraints, regulatory regions are often conserved across even widely separated species. Most proximal promoters show strong conservation, while about $60 \%$ of gene enhancers are also conserved [7]. Computer programs to identify conserved DNA sequences are helpful, but those that identify conserved patterns of TF-binding sites, even if they differ in underlying sequence, are more useful [19]. Of course, conservation provides only candidate regions. These must be cloned, inserted usually upstream from a reporter gene in a gene therapy vector, and expressed. Expression in cell lines can be suggestive, but in vivo expression is the ultimate test of regulatory construct specificity, either in terms of cellular or temporal specificity.

DNA segments extensive enough to contain the relevant regulatory elements may be too large to fit into a gene therapy vector. In this case, the regulatory elements must be identified, and unnecessary DNA edited out. Control of gene expression with such an edited promoter must then be verified. This requires in vivo analysis since in vitro responses can be quite different from those seen in the intact organism [20].

Regarding conditional promoters, binding sites for nuclear receptors can be added to many promoters to make them dependent upon ligands. However, this process does not work for all promoters. The conditional response element may disrupt normal promoter function, or may fail to regulate promoter activity [21]. Again, the function of the conditional promoter must be verified in vivo.

\section{Gene-Regulatory Elements for Use in the Inner Ear}

As noted above, the inner ear is a highly complex organ with many distinct cell types that contribute to its structure and function. Moreover, the development of the ear requires exceptional coordination amongst these and other cells in both the temporal and spatial domains [22]. Thus the differential regulation of genes in the inner ear is extraordinarily complex. Even in the adult inner ear, many different genes must be expressed appropriately for the processes of auditory transduction and neural encoding to occur. During development, hundreds if not thousands of genes must be differentially expressed in various cell types and for varying periods of time. It is presumably for this reason that so many mutations have been found to affect the inner ear: more than 400 genetic syndromes include 
hearing loss as part of the phenotype [23], nearly 150 nonsyndromic deafness loci have been linked, and more than 60 nonsyndromic genes have been identified [http://webh01.ua.ac.be/ $\mathrm{hhh} / \mathrm{]}$. It is estimated that mutations in more than 300 additional genes may produce inherited hearing loss. The diversity of mutations means that application of gene therapy to the inner ear will be challenging, with the need to produce gene products in many different cell types, and in many instances for restricted periods of time during development. Thus the cellular and temporal targeting of gene therapy may be particularly important for the inner ear.

Of course, not all gene therapy may need to be targeted to a particular cell type. For example, if delivery of a survival gene to hair cells (HCs) or spiral ganglion neurons (SGNs) was desired to protect them from a transient insult such as ototoxicity, it might not matter if the gene were also delivered to the surrounding cells. In contrast, if the gene product alters the function or structure of a cell, it would be more likely to be deleterious if expressed in the wrong cell type.

The utilization of cell- or temporally-specific gene promoters to target gene expression is an effective means of controlling gene therapy. However, it should be noted that this is not the only manner in which targeting might be achieved. An alternative is to use a vector that exhibits preferential entry into only certain cell types. For example, some herpes viruses preferentially enter neurons [24], while different isotypes of adeno-associated virus show different cellular tropisms, which can be expanded through molecular engineering [25]. This aspect of targeting is discussed in other articles of this volume. Also, the transduction of cells via viral vectors is temporary, thus delivery at the appropriate time might be achieved by the appropriate timing of delivery. However, when these strategies are not practical, promoter control of gene therapy would be appropriate.

The ideal gene promoter for use in an inner ear cell type would be expressed in that cell type, and in no other cell. In the case of the adult inner ear, it would be expressed constitutively throughout the adult life of the cell. In the case of developmental gene therapy, it would be expressed at the time required for effective treatment of the targeted disorder.

Fortunately, the existence of diverse gene expression patterns provides ample genetic resources with which to target genes to the inner ear. While relatively few genes are expressed in the inner ear and nowhere else in the body, many genes have been shown to have expression patterns that are localized to particular cells within the inner ear. Given that gene therapy vectors can be delivered locally to the labyrinth, the promoters of such genes are good candidates for use in targeting gene delivery to inner ear cells. This is particularly true for inner ear neurons, given that there are many neural-specific genes from which promoters have been isolated.

\section{Potential Cell-Specific Regulators of Inner Ear Gene Expression}

Any gene that is selectively expressed in cells of the inner ear contains regulatory elements that could potentially be used to target gene expression. Not all such elements are necessarily suitable for this purpose. As noted above, enhancers/repressors can be located 
many thousands of bases away from the expressed sequence of a gene, and the identification of targeting regulatory sequences may not always be possible. However, in the majority of genes, enhancers and repressors are close enough to be identified, albeit this process typically requires considerable effort. If the natural sequence is too large for gene therapy vectors it can often be edited. A small number of promoters and enhancers that direct gene expression to cochlear cells have already been identified.

\section{Hair Cells}

Arguably the most obvious target for gene therapy of the inner ear is the HC. This highly specialized cell is central to the auditory and vestibular transduction process. Many of the genes responsible for inherited hearing loss are expressed in the HC, and their mutation primarily affects this cell type. Expressing therapeutic sequences in HCs is thus desirable, while expressing $\mathrm{HC}$ genes in other cochlear cells could well have deleterious effects on function. Therefore HC-specific promoters are of special interest for inner ear gene therapy.

There are a moderately large number of genes that are expressed in HCs but not in other types of cochlear cells. These are expressed at various periods in the life cycle of the cell, and thus could provide gene therapy at different developmental periods. A list of genes whose promoters could be used for this purpose is provided in table 1. In some cases, the promoters for these genes have been partially isolated and characterized.

The results of attempts at regulatory sequence isolation are informative. For example, the prestin gene is expressed in outer $\mathrm{HCs}$, where it mediates electromotility and the active cochlear amplifier. When DNA fragments from the $5^{\prime}$ region of the gene and the first intron were cloned and linked to a reporter in transgenic mice, expression was observed in inner and vestibular HCs, and in SGNs, but not in outer HCs [32].

An analysis of the Myo7A promoter by Boëda et al. [34] found that $118 \mathrm{bp} 5^{\prime}$ to the transcription initiation site, plus $\sim 2 \mathrm{~kb}$ consisting of the first exon and intron of the gene, were sufficient to drive expression that closely mimicked that of Myo7A in the inner ear, specific to HCs after their formation. Neither the $5^{\prime} 118$ bp nor the intron alone produced expression, so both regulatory elements were required.

A construct consisting of $1.7 \mathrm{~kb}$ located $3^{\prime}$ to the expressed sequence of the murine atohl (mathl) gene produces expression in HCs of the inner ear, from fate specification through postnatal development (fig. 3), but not in adult HCs. This was found to be related to two highly conserved enhancer elements within the region. Interestingly, either enhancer could produce $\mathrm{HC}$ expression, indicating a high degree of redundancy. Moreover, both enhancers also drove expression in most other tissues that express Atoh1, thus the enhancer is not cellspecific. The enhancer construct also produces some expression in supporting cells, which is not observed in the atohl gene.

A construct consisting of $400 \mathrm{bp} 5^{\prime}$ to the POU4F3 gene does not produce expression in HCs. In contrast, $8.5 \mathrm{~kb} 5^{\prime}$ to the $P O U 4 F 3$ gene produces expression that, in the postnatal mouse inner ear, is limited to HCs [39]. Expression begins shortly after $\mathrm{HC}$ fate is adopted, and it is present in all cochlear and vestibular HCs through the first 2 weeks of life. 
However, this fragment also produces expression in ganglion neurons prenatally, and produces less expression in adult outer HCs than is characteristic of the POU4F3 gene [29]. This presumably reflects the absence of enhancer and repressor elements located elsewhere in the gene.

This illustrates a common problem with enhancer/promoter constructs. They usually do not replicate the expression pattern of the gene with complete fidelity, due to an incomplete complement of regulatory elements, or to potential differences in secondary structure or epigenetic alterations of construct DNA when compared to native DNA. Other posttranscriptional regulatory mechanisms may also generate differences between the gene products of a native gene and a transgene. MicroRNAs targeted to regions of the native transcript may degrade it prior to translation [12] in ways that do not occur in the transcript as encoded by the gene therapy vector, since introns and other untranslated regions are often deleted.

\section{Supporting Cells}

Another important target for gene therapy is the supporting cells of the sensory epithelia. The most common inherited form of nonsyndromic deafness is due to mutations in the gene encoding connexin 23 [40], which is highly expressed in adult supporting cells but not in HCs [41]. Other genes expressed selectively in supporting cells include $\alpha$ - and $\beta$-tectorin, which are components of the acellular membrane that lie above the inner ear sensory epithelia. The supporting cell antigen is a protein of unknown function that is highly expressed in supporting cells [42]. The cell cycle regulator, p27/Kip1, is expressed in developing supporting cells, but not HCs [43]. A p27/Kip1 construct that directs expression to the inner ear has been generated by recombination in a bacterial artificial chromosome, but the regulatory sequences have not been further localized [44]. FGF receptor 3 is expressed in developing pillar cells and Deiter's cells of the cochlea [45]. A promoter for this gene has been isolated and defined [46], but not for the inner ear. The LIM-domain protein Islet 1 is expressed in developing HCs and supporting cells, but in adulthood becomes restricted to supporting cells [47]. None of the regulatory elements that direct the expression of these or other genes to supporting cells have been characterized, but given the number of candidates this should certainly be possible.

\section{Inner Ear Ganglion Neurons}

The SGNs are the only neurons whose cell bodies are found within the cochlea. Thus a wide variety of genes with expression that is restricted to neurons could supply promoters for use with locally applied gene therapy vectors. This includes a variety of genes encoding neuronspecific structural proteins such as neurofilaments, neurotransmitter receptors such as GluR2 or GluR3. Similarly, many neuron-specific developmental genes are expressed only in the neurons of the inner ear. This includes TFs such as POU4F1 and POU4F2 [28, 48].

Differentiation between type I and type II SGNs could be achieved using the promoter of the peripherin gene [49], which is only expressed in type II neurons [50]. 


\section{Stria Vascularis}

Inherited deafness can be caused by mutation of a number of genes normally expressed in the stria vascularis, due to its critical function as an ion transport epithelium and generator of the endocochlear potential. A number of these genes are preferentially expressed in the stria vascularis, and not in other cochlear tissues. For example, the gene encoding the $\beta 2$ subunit of Na,K-ATPase is expressed in the marginal, intermediate and basal cells of the stria during late development and adulthood [51]. Bioinformatic analysis of the gene indicates $768 \mathrm{bp}$ of a highly conserved sequence immediately $5^{\prime}$ to the CAP site, suggesting promoter/enhancer elements that may control tissue-specific expression [52], although this has not been tested in the inner ear. The genes encoding the KVLQT1 and IsK potassium channels, and ubiquitin A-52, are expressed only in the marginal cells, again in late development and adulthood [53-55]. Promoters for the potassium channel genes have yet to be isolated. However the $u b a 52$ promoter region has been partially characterized [56].

\section{Spiral Ligament}

Recent observations have supported the concept that the spiral ligament is a very active participant in cochlear function, serving as a site for ion transport between the perilymph and stria vascularis [57] and perhaps serving other functions. This is consistent with the level of glucose metabolism that has been observed in the ligament [58], which equals that of the stria. Genes that are selectively expressed at this site include Crym, found in fibrocytes of the ligament, and collagen type IX, found in type II fibrocytes [55].

\section{Other Promoters}

In addition to genes that are normally expressed in tissues, some altered, viral or hybrid promoters have been found to be expressed selectively in cochlear tissues. This is presumably due to the fortuitous presence of binding sites for regulatory factors that are present in cochlear cells. An example of this is the human elongation factor 1a promoter (fig. 4), which for unknown reasons induces expression preferentially in cells of the organ of Corti [59]. Neuron-specific promoters have also been generated artificially. A mutated form of the thyl promoter has been shown to drive expression in neurons, with integration into different sites producing expression in different subsets of neurons [60], including SGNs (fig. 5).

\section{Potential Limitations}

The isolation of functional cell-specific regulatory sequences is not always possible due to distant enhancers or lack of sufficient homology for identification. Moreover, many of the regulatory sequences that have been isolated, as listed above, have been characterized in transgenic models in which the promoter is integrated into the genome. However, regulatory sequences may behave differently in a viral vector. This can be due to changes in the conformation of the DNA due to vector DNA. Alternatively, the state of acetylation or methylation of nuclear proteins or DNA within in the regulatory sequence may be different in a viral vector than in native DNA. Artificial DNA introduced into cells has been shown to be associated with histones, but in a manner different to that seen in the genome [61]. Viruses also produce their own histone-like proteins that can be acetylated [62] and that may 
interact with transgene-regulatory sequences. Interestingly, inhibitors of histone deactylation have been shown to significantly increase viral vector transduction of mammalian cells [63], implicating acetylation as an important factor in viral vector gene expression. This has recently been found to be true for transduction of cells in the organ of Corti by adenovirus vectors [64].

\section{Conclusions}

The delivery of gene therapy to specific cochlear cells will be aided by the use of generegulatory mechanisms that occur naturally in cochlear cells. It is clear from the above discussion that many combinations of gene promoters and enhancers are available that could be used to target gene delivery to particular cochlear cells. Additional regulatory sequences are sure to be discovered as the characterization of genes expressed in the inner ear continues. As enhancers that direct expression to particular inner ear cell types are better understood, it will also be possible to engineer vectors that combine different features. Thus it will be possible to use enhancers to direct expression to a cell type, via a promoter that can be separately regulated. The most obvious example would be to combine enhancers that direct expression to a particular cell type, with conditional promoters that can be turned on or off by the application of an endogenous agent such as a Tet-On response element. The promise of regulatory control of gene therapy vectors seems great.

\section{References}

1. Bazan-Peregrino M, Seymour LW, Harris AL. Gene therapy targeting to tumor endothelium. Cancer Gene Ther. 2007; 14:117-127. [PubMed: 17096029]

2. Friedmann, T. Gene Therapy: Fact and Fiction in Biology's New Approaches to Disease. Woodbury: CSHL Press; 1994.

3. Lodish, H.; Berk, A.; Zipursky, S.; Lawrence, S.; Matsudaira, P.; Baltimore, D.; Darnell, J., editors. Molecular Cell Biology. New York: Freeman; 1999.

4. Schones DE, Zhao K. Genome-wide approaches to studying chromatin modifications. Nat Rev Genet. 2008; 9:179-191. [PubMed: 18250624]

5. Verdone L, Agricola E, Caserta M, Di Mauro E. Histone acetylation in gene regulation. Brief Funct Genomic Proteomic. 2006; 5:209-221. [PubMed: 16877467]

6. Zhang Y, Reinberg D. Transcription regulation by histone methylation: interplay between different covalent modifications of the core histone tails. Genes Dev. 2001; 15:2343-2360. [PubMed: 11562345]

7. Heintzman ND, Stuart RK, Hon G, Fu Y, Ching CW, Hawkins RD, Barrera LO, Van Calcar S, Qu C, Ching KA, Wang W, Weng Z, Green RD, Crawford GE, Ren B. Distinct and predictive chromatin signatures of transcriptional promoters and enhancers in the human genome. Nat Genet. 2007; 39:311-318. [PubMed: 17277777]

8. Leonhardt H, Rahn HP, Cardoso MC. Functional links between nuclear structure, gene expression, DNA replication, and methylation. Crit Rev Eukaryot Gene Expr. 1999; 9:345-351. [PubMed: 10651251]

9. Haines TR, Rodenhiser DI, Ainsworth PJ. Allele-specific non-CpG methylation of the Nf1 gene during early mouse development. Dev Biol. 2001; 240:585-598. [PubMed: 11784085]

10. Lobe CG. Transcription factors and mammalian development. Curr Top Dev Biol. 1992; 27:351383. [PubMed: 1424766]

11. Davidson, EH. The Regulatory Genome: Gene Regulatory Networks in Development and Evolution. New York: Academic Press; 2006. 
12. Chen K, Rajewsky N. The evolution of gene regulation by transcription factors and microRNAs. Nat Rev Genet. 2007; 8:93-103. [PubMed: 17230196]

13. Hallikas O, Palin K, Sinjushina N, Rautiainen R, Partanen J, Ukkonen E, Taipele J. Genome-wide prediction of mammalian enhancers based on analysis of transcription factor binding affinity. Cell. 2006; 24:47-59. [PubMed: 16413481]

14. Sipo I, Wang X, Hurtado Picó A, Suckau L, Weger S, Poller W, Fechner H. Tamoxifen-regulated adenoviral E1A chimeras for the control of tumor selective oncolytic adenovirus replication in vitro and in vivo. Gene Ther. 2006; 13:173-186. [PubMed: 16136163]

15. Fechner H, Wang X, Picó AH, Wildner J, Suckau L, Pinkert S, Sipo I, Weger S, Poller W. A bidirectional Tet-dependent promotor construct regulating the expression of E1A for tight control of oncolytic adenovirus replication. J Biotechnol. 2007; 127:560-574. [PubMed: 17083991]

16. Fickett JW, Hatzigeorgiou AG. Eukaryotic promoter recognition. Genome Res. 1997; 7:861-878. [PubMed: 9314492]

17. Visel A, Bristow J, Pennacchio LA. Enhancer identification through comparative genomics. Semin Cell Dev Biol. 2007; 18:140-152. [PubMed: 17276707]

18. Heintzman ND, Ren B. The gateway to transcription: identifying, characterizing and understanding promoters in the eukaryotic genome. Cell Mol Life Sci. 2007; 64:386-400. [PubMed: 17171231]

19. Xie D, Cai J, Chia NY, Ng HH, Zhong S. Cross-species de novo identification of cis-regulatory modules with GibbsModule: application to gene regulation in embryonic stem cells. Genome Res. 2008; 18:1325-1335. [PubMed: 18490265]

20. Oosterveen T, van Vliet P, Deschamps J, Meijlink F. The direct context of a hox retinoic acid response element is crucial for its activity. J Biol Chem. 2003; 278:24103-24107. [PubMed: 12697756]

21. Houdebine LM. Methods to generate transgenic animals and to control transgene expression. J Biotechnol. 2002; 98:145-160. [PubMed: 12141984]

22. Friedman LM, Dror AA, Avraham KB. Mouse models to study inner ear development and hereditary hearing loss. Int J Dev Biol. 2007; 51:609-631. [PubMed: 17891721]

23. Toriello, HV.; Reardon, W.; Gorlin, HJ. Hereditary Hearing Loss and Its Syndromes. Oxford: Oxford University Press; 2004.

24. Frampton AR Jr, Goins WF, Nakano K, Burton EA, Glorioso JC. HSV trafficking and development of gene therapy vectors with applications in the nervous system. Gene Ther. 2005; 12:891-901. [PubMed: 15908995]

25. Kwon I, Schaffer DV. Designer gene delivery vectors: molecular engineering and evolution of adeno-associated viral vectors for enhanced gene transfer. Pharm Res. 2008; 25:489-499. [PubMed: 17763830]

26. Bermingham NA, Hassan BA, Price SD, Vollrath MA, Ben-Arie N, Eatock RA, Bellen HJ, Lysakowski A, Zoghbi HY. Math1:an essential gene for the generation of inner ear hair cells. Science. 1999; 284:1837-1841. [PubMed: 10364557]

27. Lumpkin EA, Collisson T, Parab P, Omer-Abdalla A, Haeberle H, Chen P, Doetzlhofer A, White $\mathrm{P}$, Groves A, Segil N, Johnson JE. Math1-driven GFP expression in the developing nervous system of transgenic mice. Gene Expr Patterns. 2003; 3:389-395. [PubMed: 12915300]

28. Erkman L, McEvilly RJ, Luo L, Ryan AK, Hooshmand F, O'Connell SM, Keithley EM, Rapaport DH, Ryan AF, Rosenfeld MG. Role of transcription factors Brn-3.1 and Brn-3.2 in auditory and visual system development. Nature. 1996; 381:603-606. [PubMed: 8637595]

29. Ryan AF, Dulon D, Pak K, Mullen L, Li Y, Erkman L. Developmental regulation of pou $4 f 3$ gene expression by 5' DNA. Submitted. 2009

30. Hertzano R, Dror AA, Montcouquiol M, Ahmed ZM, Ellsworth B, Camper S, Friedman TB, Kelley MW, Avraham KB. Lhx3, a LIM domain transcription factor, is regulated by Pou4f3 in the auditory but not in the vestibular system. Eur J Neurosci. 2007; 25:999-1005. [PubMed: 17331196]

31. Zheng J, Shen W, He DZ, Long KB, Madison LD, Dallos P. Prestin is the motor protein of cochlear outer hair cells. Nature. 2000; 405:149-155. [PubMed: 10821263] 
32. Tian Y, Li M, Fritzsch B, Zuo J. Creation of a transgenic mouse for hair-cell gene targeting by using a modified bacterial artificial chromosome containing Prestin. Dev Dyn. 2004; 231:199-203. [PubMed: 15305300]

33. Gibson F, Walsh J, Mburu P, Varela A, Brown KA, Antonio M, Beisel KW, Steel KP, Brown SD. A type VII myosin encoded by the mouse deafness gene shaker-1. Nature. 1995; 374:62-64. [PubMed: 7870172]

34. Boëda B, Weil D, Petit C. A specific promoter of the sensory cells of the inner ear defined by transgenesis. Hum Mol Genet. 2001; 10:1581-1589. [PubMed: 11468276]

35. Hasson T, Gillespie PG, Garcia JA, MacDonald RB, Zhao Y, Yee AG, Mooseker MS, Corey DP. Unconventional myosins in inner-ear sensory epithelia. J Cell Biol. 1997; 137:1287-1307. [PubMed: 9182663]

36. Sakaguchi N, Henzl MT, Thalmann I, Thalmann R, Schulte BA. Oncomodulin is expressed exclusively by outer hair cells in the organ of Corti. J Histochem Cytochem. 1998; 46:29-40. [PubMed: 9405492]

37. Park HJ, Niedzielski AS, Wenthold RJ. Expression of the nicotinic acetylcholine receptor subunit, alpha9, in the guinea pig cochlea. Hear Res. 1997; 112:95-105. [PubMed: 9367232]

38. Elgoyhen AB, Vetter DE, Katz E, Rothlin CV, Heinemann SF, Boulter J. Alpha10: a determinant of nicotinic cholinergic receptor function in mammalian vestibular and cochlear mechanosensory hair cells. Proc Natl Acad Sci USA. 2001; 98:3501-3506. [PubMed: 11248107]

39. Sage C, Huang M, Vollrath MA, Brown MC, Hinds PW, Corey DP, Vetter DE, Chen ZY. Essential role of retinoblastoma protein in mammalian hair cell development and hearing. Proc Natl Acad Sci USA. 2006; 103:7345-7350. [PubMed: 16648263]

40. Zelante L, Gasparini P, Estivill X, Melchionda S, D’Agruma L, Govea N, Milá M, Monica MD, Lutfi J, Shohat M, Mansfield E, Delgrosso K, Rappaport E, Surrey S, Fortina P. Connexin26 mutations associated with the most common form of non-syndromic neurosensory autosomal recessive deafness (DFNB1) in Mediterraneans. Hum Mol Genet. 1997; 6:1605-1609. [PubMed: 9285800]

41. Kikuchi T, Adams JC, Paul DL, Kimura RS. Gap junction systems in the rat vestibular labyrinth: immunohistochemical and ultrastructural analysis. Acta Otolaryngol. 1994; 114:520-528. [PubMed: 7825434]

42. Zajic G, Nair TS, Ptok M, Van Waes C, Altschuler RA, Schacht J, Carey TE. Monoclonal antibodies to inner ear antigens: I. Antigens expressed by supporting cells of the guinea pig cochlea. Hear Res. 1991; 52:59-71. [PubMed: 2061214]

43. Löwenheim H, Furness DN, Kil J, Zinn C, Gültig K, Fero ML, Frost D, Gummer AW, Roberts JM, Rubel EW, Hackney CM, Zenner HP. Gene disruption of p27(Kip1) allows cell proliferation in the postnatal and adult organ of Corti. Proc Natl Acad Sci USA. 1999; 96:4084-4088. [PubMed: 10097167]

44. Doetzlhofer A, White P, Lee YS, Groves A, Segil N. Prospective identification and purification of hair cell and supporting cell progenitors from the embryonic cochlea. Brain Res. 2006; 1091:282288. [PubMed: 16616734]

45. Pirvola U, Cao Y, Oellig C, Suoqiang Z, Pettersson RF, Ylikoski J. The site of action of neuronal acidic fibroblast growth factor is the organ of Corti of the rat cochlea. Proc Natl Acad Sci USA. 1995; 92:9269-9273. [PubMed: 7568115]

46. McEwen DG, Ornitz DM. Regulation of the fibroblast growth factor receptor 3 promoter and intron I enhancer by Sp1 family transcription factors. J Biol Chem. 1998; 273:5349-5357. [PubMed: 9478995]

47. Radde-Gallwitz K, Pan L, Gan L, Lin X, Segil N, Chen P. Expression of Islet1 marks the sensory and neuronal lineages in the mammalian inner ear. J Comp Neurol. 2004; 477:412-421. [PubMed: 15329890]

48. McEvilly RJ, Erkman L, Luo L, Sawchenko PE, Ryan AF, Rosenfeld MG. Requirement for Brn-3.0 in differentiation and survival of sensory and motor neurons. Nature. 1996; 384:574-577. [PubMed: 8955272] 
49. Leconte L, Santha M, Fort C, Poujeol C, Portier MM, Simonneau M. Cell type-specific expression of the mouse peripherin gene requires both upstream and intragenic sequences in transgenic mouse embryos. Brain Res Dev Brain Res. 1996; 92:1-9.

50. Hafidi A, Després G, Romand R. Ontogenesis of type II spiral ganglion neurons during development: peripherin immunohistochemistry. Int J Dev Neurosci. 1993; 11:507-512. [PubMed: 8237466]

51. Fina M, Ryan AF. Expression of mRNAs encoding alpha and beta subunit isoforms of Na,KATPase in the vestibular labyrinth and endolymphatic sac of the rat. Mol Cell Neurosci. 1994; 5:604-613. [PubMed: 7704435]

52. Shyjan AW, Canfield VA, Levenson R. Evolution of the Na,K- and H,K-ATPase beta subunit gene family: structure of the murine Na,K-ATPase beta 2 subunit gene. Genomics. 1991; 11:435-442. [PubMed: 1663071]

53. Neyroud N, Tesson F, Denjoy I, Leibovici M, Donger C, Barhanin J, Fauré S, Gary F, Coumel P, Petit C, Schwartz K, Guicheney P. A novel mutation in the potassium channel gene KVLQT1 causes the Jervell and Lange-Nielsen cardioauditory syndrome. Nat Genet. 1997; 15:186-189. [PubMed: 9020846]

54. Sakagami M, Fukazawa K, Matsunaga T, Fujita H, Mori N, Takumi T, Ohkubo H, Nakanishi S. Cellular localization of rat Isk protein in the stria vascularis by immunohistochemical observation. Hear Res. 1991; 56:168-172. [PubMed: 1663105]

55. Usami S, Takumi Y, Suzuki N, Oguchi T, Oshima A, Suzuki H, Kitoh R, Abe S, Sasaki A, Matsubara A. The localization of proteins encoded by CRYM, KIAA1199, UBA52, COL9A3, and COL9A1, genes highly expressed in the cochlea. Neuroscience. 2008; 154:22-28. [PubMed: 18448257]

56. Sun L, Pan X, Wada J, Haas CS, Wuthrich RP, Danesh FR, Chugh SS, Kanwar YS. Isolation and functional analysis of mouse UbA52 gene and its relevance to diabetic nephropathy. J Biol Chem. 2002; 277:29953-29962. [PubMed: 12171997]

57. Steel KP. Perspectives: biomedicine. The benefits of recycling. Science. 1999; 285:1363-1364. [PubMed: 10490411]

58. Ryan AF, Goodwin P, Woolf N, Sharp FR. Auditory stimulation alters the pattern of 2deoxyglucose uptake in the inner ear. Brain Res. 1982; 234:213-225. [PubMed: 7059827]

59. Brigande JV, Gubbels SP, Woessner DW, Jungwirth JJ, Bresee CS. Electroporation-mediated gene transfer to the developing mouse inner ear. Methods Mol Biol. 2009; 493:125-139. [PubMed: 18839345]

60. Feng G, Mellor RH, Bernstein M, Keller-Peck C, Nguyen QT, Wallace M, Nerbonne JM, Lichtman JW, Sanes JR. Imaging neuronal subsets in transgenic mice expressing multiple spectral variants of GFP. Neuron. 2000; 28:41-51. [PubMed: 11086982]

61. Cereghini S, Yanic M. Assembly of transfected DNA into chromatin: structural changes in the origin-promoter-enhancer region upon replication. EMBO J. 1984; 3:1243-1253. [PubMed: 6086311]

62. Fedor MJ, Daniell E. Acetylation of histone-like proteins of adenovirus type 5. J Virol. 1980; 35:637-643. [PubMed: 7420537]

63. Kitazono M, Chuman Y, Aikou T, Fojo T. Construction of gene therapy vectors targeting thyroid cells: enhancement of activity and specificity with histone deacetylase inhibitors and agents modulating the cyclic adenosine 3,5-monophosphate pathway and demonstration of activity in follicular and anaplastic thyroid carcinoma cells. J Clin Endocrinol Metab. 2001; 86:834-840. [PubMed: 11158054]

64. Taura A, Taura K, Choung YH, Masuda M, Pak K, Chavez E, Ryan AF. Histone deacetylase inhibition enhances adenoviral vector transduction in inner ear tissue. Submitted. 2009 


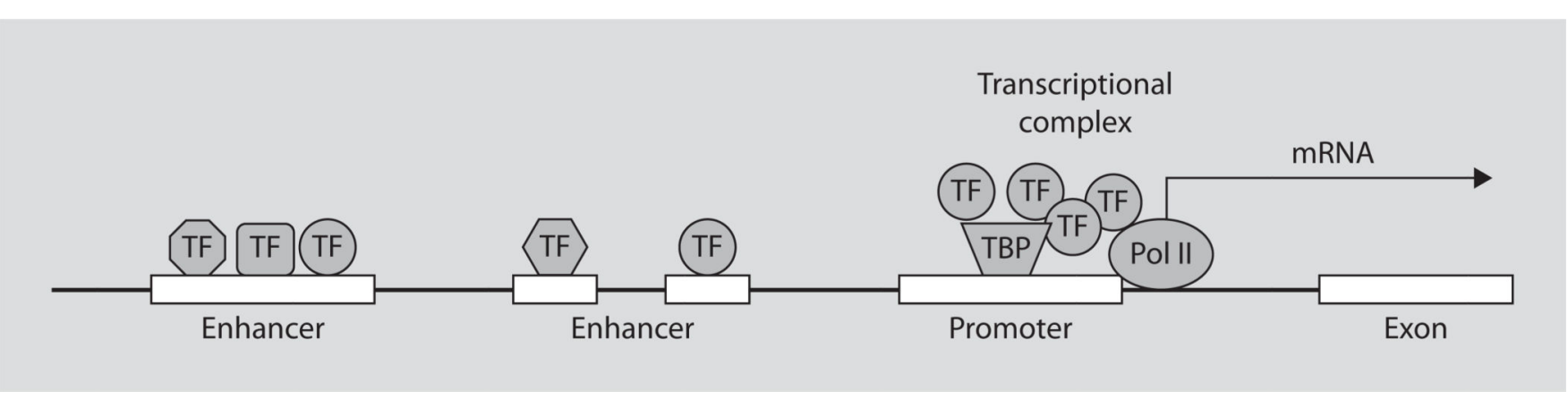

Figure 1.

Schematic representation of gene regulation. The core promoter of a gene lies immediately upstream of the transcription initiation site at which mRNA production by RNA polymerase II (Pol II) begins. The promoter serves as a binding site for the transcription complex, which consists of Poll II, various transcription factors (TFs), and for promoters containing a TATA box, the TATA-binding protein (TBP). At other locations in the gene, enhancers serve as binding sites for additional TFs and can influence the rate of transcription of the gene. Binding of different combinations of TFs can direct expression to different cell types or times. 


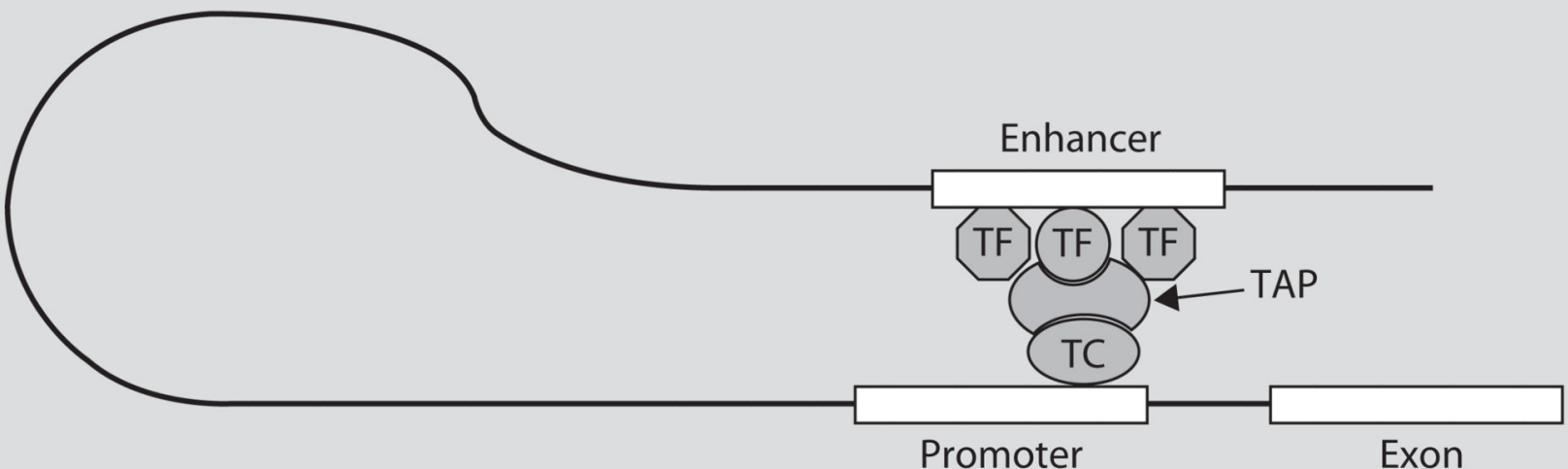

Figure 2.

Schematic representation of the means by which enhancers are thought to influence the transcriptional complex (TC). Transcription factors (TFs) that are bound to their DNA recognition DNA motifs in an enhancer are brought into contact with the TC by the folding of DNA. Either the TFs or a transcription-associated protein (TAP) interact with the TC via a transactivation domain. Many promoters are inactive without the influence of enhancers. 

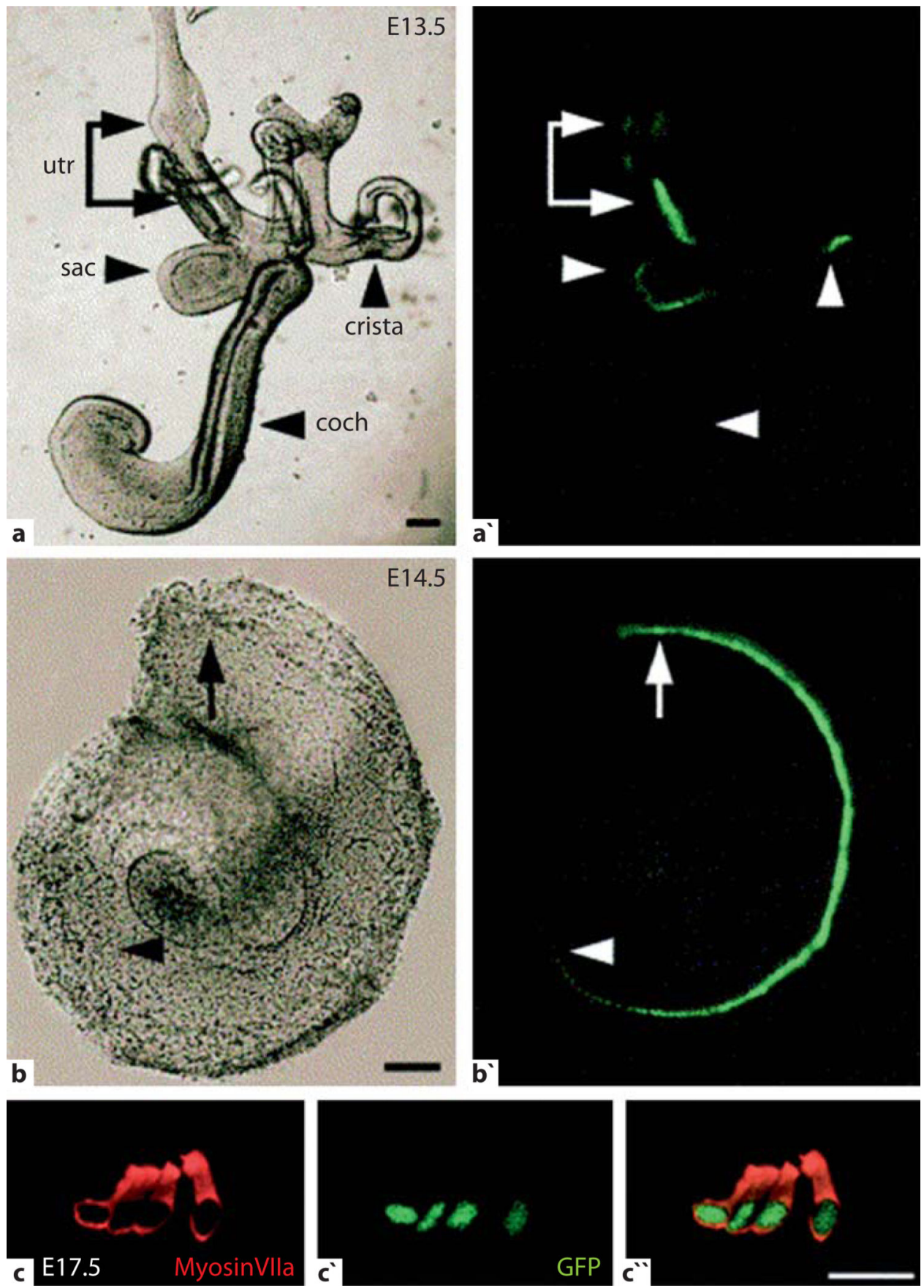

Figure 3.

Expression of green fluorescent protein (GFP) driven by regulatory elements from the atohl gene, in the inner ear of transgenic mice. a Entire membranous labyrinth at E13.5. The sensory organs of the vestibular system, including the utricle (utr), saccule (sac), and crista, which contain differentiating hair cells (HCs), express GFP. The more immature cochlea (coch), in which HCs have yet to develop, does not. b Dissected cochlea at E14.5. HCs have now developed through 1.5 turns. The arrow indicates the basal region where $\mathrm{HC}$ differentiation initiates, arrowhead indicates the leading edge of $\mathrm{HC}$ differentiation as shown 
by the extent of GFP-expressing HCs. Scale bars equal $100 \mu \mathrm{m}$. c Confocal image of E176.5 organ of Corti [27]. 
a

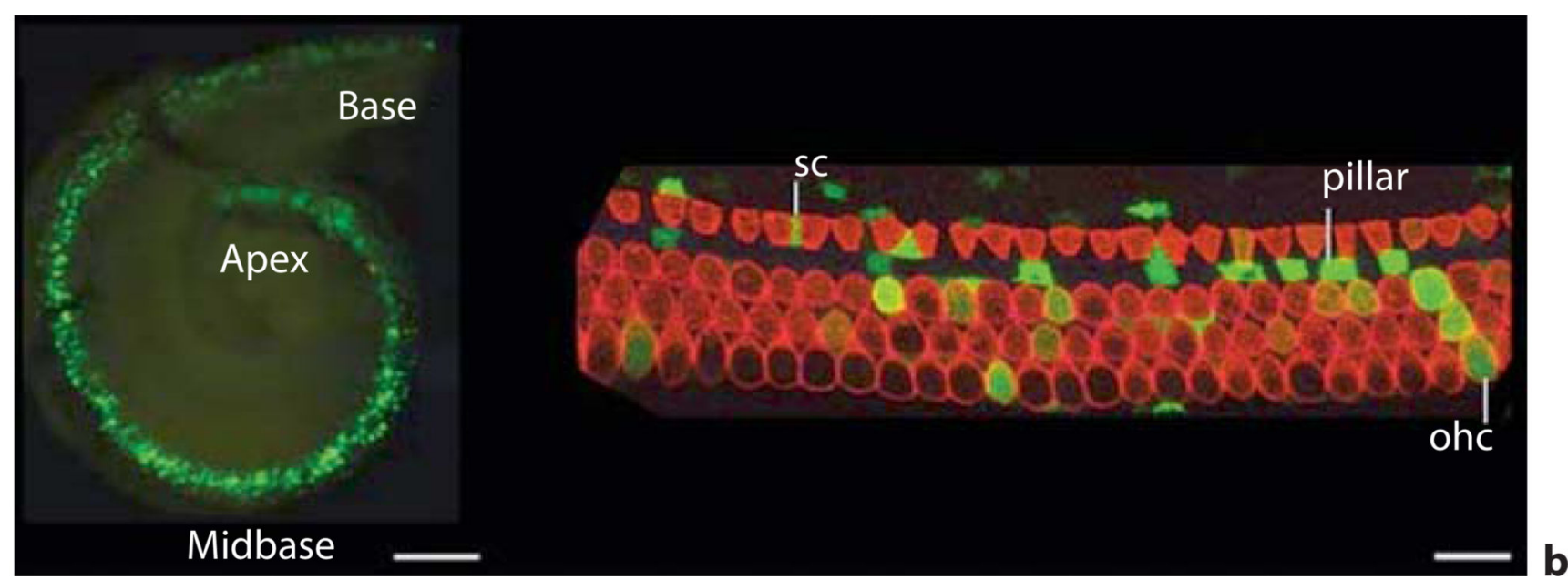

Figure 4.

Expression of green fluorescent protein (GFP) driven by the human elongation factor 1a (efla) promoter in the organ of Corti of the mouse. Plasmid DNA was electroporated into the E11.5 mouse otocyst. The inner ear was fixed and processed for histochemistry at E17.5 [59]. 




a

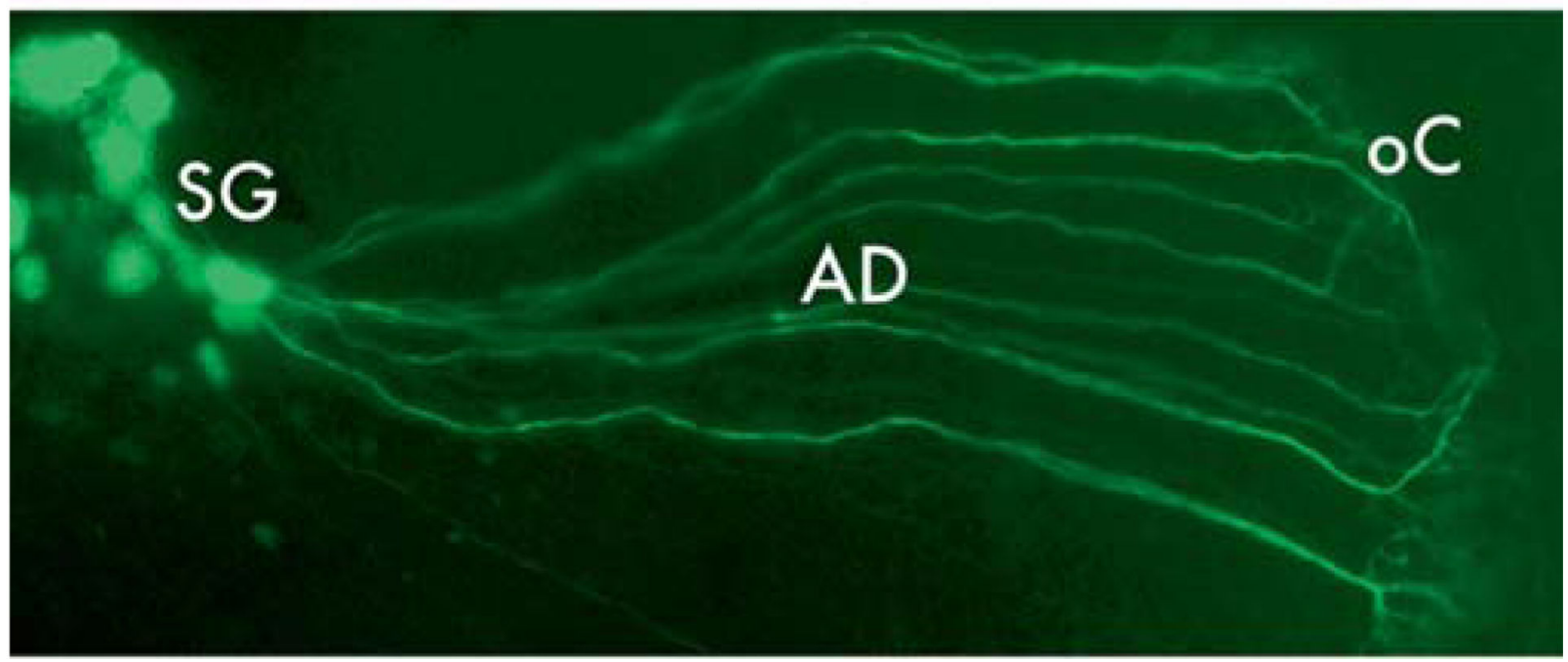

Figure 5.

Expression of yellow fluorescent protein, driven by an altered thyl promoter, in the neurons of the neonatal spiral ganglion of a transgenic mouse. a Neuronal somata in the spiral ganglion (SG) are intensely labeled, as are afferent dendrites (AD) and a dense plexus of nerve terminals underneath the inner hair cells $(\mathrm{HCs})$ in the organ of Corti $(\mathrm{oC})$. b Higher magnification image of SG neurons and their dendrites, with branching terminations under the inner HCs characteristic of this developmental stage. 
Table 1

A selection of hair cell-specific genes

\begin{tabular}{lllll}
\hline Gene & Time of expression & Hair cells & $\begin{array}{l}\text { Regulatory } \\
\text { sequence isolated }\end{array}$ & References \\
\hline Atoh1 & Developmental & All & yes & $\begin{array}{l}\text { Bermingham et al. [26], } \\
\text { Lumpkin et al. [27] }\end{array}$ \\
\hline POU4F3 & Developmental, adult & All & Yes & $\begin{array}{l}\text { Erkman et al. [28], } \\
\text { Ryan et al. [29] }\end{array}$ \\
\hline Lhx3 & Developmental, adult & All & No & Hertzano et al. [30] \\
\hline Prestin & Adult & OHCs & Yes & $\begin{array}{l}\text { Zheng et al. [31], } \\
\text { Tian et al. [32] }\end{array}$ \\
\hline Myo7A & Developmental,adult & All & Yes & $\begin{array}{l}\text { Gibson et al. [33], } \\
\text { Boëda et al. [34] }\end{array}$ \\
\hline Myo6 & Developmental, adult & All & No & Hasson et al. [35] \\
\hline Oncomod & Adult & OHCs & No & Sakaguchi et al. [36] \\
\hline a9AchR & Developmental, adult & All & No & Park et al. [37] \\
\hline a10AchR & Developmental, adult & All & No & Elgoyhen et al. [38] \\
\hline
\end{tabular}

OHCs $=$ Outer hair cells. 